\title{
Diffusion of Crossbred Cow Technology in Smallholder Dairy Sector in Sri Lanka
}

\author{
Amila Nandadasa and Jagath Edirisinghe*
}

\begin{abstract}
Crossbred cow technology is a potent innovation in the dairy industry in the developing world where a vast majority of producers is smallholders. Having animals with high yielding abilities has a marked impact on smallholder's income and thus their standards of living. In this research an attempt was made to study the variables affected on time taken for adoption of this technology, obtaining samples of data from selected regions of Sri Lanka. We employed a duration analysis and used four models frequently used in literature: the Cox, Exponential, Gompertz and Weibull Proportional Hazard models. We employed a duration analysis to examine the impact of important covariates on the speed of adoption of crossbreeds in the smallholder sector. Our sample comprised of 201 smallholder farmers selected from three major agro-climatic zones in the country. Empirical results highlighted the importance of human and social capital on accelerated adoption.
\end{abstract}

Keywords: Cox model, Crossbred cow adoption, Duration analysis, Exponential model, Gompertz model, Weibul model

\section{INTRODUCTION}

A crossbreed is an animal with purebred parents of two different breeds, varieties, or populations while crossbreeding is the process of breeding an animal with the purpose of creating offspring that share the traits of both parents or producing an animal with hybrid vigor.

Department of Agribusiness Management, Faculty of Agriculture and Plantation Management, Wayamba University of Sri Lanka

*Jagathed07@gmail.com
Traits such as reproduction, growth, maternal ability, lead to higher productivity and therefore, profitability in dairy production. Use of crossbred animals is immensely useful in deriving economically viable levels of output in milk production in developing countries. In most of these countries, native cattle tend to produce low yields, but are quite able to withstand local weather conditions.

Therefore, crossbreeding of these local animals with high yielding imported breeds have proven quite useful in dairy industry, especially, at smallholder level. For example, crossbreeding has tripled milk production of smallholder dairy farmers in Kenya (Mtumwa and Mwasha, 1995).

However, adoption of technology is a process based on sequence of individual decisions, after which innovation is either accepted or rejected (Karshena, and Stoneman, 1995). There is still a considerable gap in knowledge on factors affecting the time taken for adoption of the technology among farmers. This is simply because adoption depends on the farmers' willingness to invest in other requirements that are associated with crossbreeds such as concentrated feeding, pregnancy testing, vaccination against contagious diseases, tick control, improved feeding, colostrum feeding to newborn calves, and overall health care of livestock (Abdulai and Haffman, 2005).

Sri Lanka has an area of 65,610 square kilometers. Approximately 75 percent of the agricultural land belongs to the smallholding sector. About 90 percent of the 1.8 million estimated smallholdings has less than 2ha of land (The Ministry of 
Livestock Development, 2007). Based on elevation, Sri Lanka divides as, low, mid and up country and based on the rainfall pattern, it divides into dry, intermediate and wet zones. There is milk production in all of the districts falling into all these zones irrespective of the elevation or the rainfall pattern. There are cross breeding programs in farms across Sri Lanka to suit each of these agro ecological zones. Despite the effort, the performance of sector is below par. Given the vast majority of smallholder farmers in the country, popularization of crossbreeds is vital in the smallholder sector to achieve the national aim, i.e. "to achieve increased self-reliance, of at least 50 percent, in domestic milk by 2015" (Ministry of Livestock Development, 2007). Faster up taking of this crossbreeding technology by smallholders is necessary to achieve this national aim.

Sri Lanka imports about 65,000 MT of dairy products. Therefore, dairy development is seen as an instrument to replace this large volume of imported commodities and to generate rural employment because, in Sri Lanka, dairying is a predominantly smallholder operation (Bandara 2001) who are keeping 2-5 cows and their followers in most of the agroecological regions. However, in the dry zone, the average herd size is larger, though the animals are mostly of the indigenous types with poor milk yields. The smallholdings sector accounts for 96 percent of the total cattle population (Department of Census and Statistics, 2002). Upgrading the native herd is a fundamental necessity for dairy development and is a key area of public investment in the national livestock development of plan of Sri Lanka. According to the last Census of Agriculture, which was in the year 2002, there was a mere $12 \%$ of improved cattle in the country (Table 1).
Table 1: Distribution of cattle among size class of the holding in 2002

\begin{tabular}{llll}
\hline $\begin{array}{l}\text { Size Class of } \\
\text { the Holding } \\
\text { (Ha) }\end{array}$ & $\begin{array}{l}\text { Local } \\
\text { Cattle }\end{array}$ & $\begin{array}{l}\text { Improved } \\
\text { Cattle }\end{array}$ & $\begin{array}{l}\text { \% of } \\
\text { Impro } \\
\text { ved } \\
\text { Cattle }\end{array}$ \\
\hline $1<$ & 638,898 & 99,614 & 13.49 \\
$1-<2$ & 192,660 & 18,360 & 8.70 \\
$2-<3$ & 45,665 & 3,882 & 7.83 \\
$3-<4$ & 11,500 & 1,052 & 8.38 \\
$4-<5$ & 11,102 & 1,080 & 8.87 \\
$5-<8$ & 7,175 & 866 & 10.77 \\
$>8$ & 5,686 & 828 & 12.71 \\
Total & 912,686 & 125,682 & 12.10 \\
\hline Source: Department of Census and Statistics (2002)
\end{tabular}

In this context, our aim was to analyze the adoption behavior over time, for crossbred technology and provide information that can improve future policies to encourage adoption.

\section{MATERIALS AND METHODS}

\section{Duration Analysis}

Duration Analysis (DA) is a statistical method widely used in analyzing adoption processes of agricultural technologies (Alcon et al., 2011). It attempts to relate a set of covariates to time-to-event (which is time to adoption in this case) data. Length of a spell (time-to-event) is started with the entry (start of dairy farming) and end after a new state (adoption of a crossbred) is achieved. Interest here is to estimate the effect of covariates that shorten/extend this time for adoption. In this context, two factors are important: the survival function and the hazard rate.

The survival function, which is denoted in (1), gives the probability that the event in question has not occurred at time' $t$ '. In relation to the present study, the survival 
function gives the probability of a farmer not adopting a crossbred at the end of the study period.

$S(t)=\operatorname{Pr}(T \geq t)=1-F(t)$

In equation (1), $\mathrm{S}(\mathrm{t})$ gives the probability that a spell is of length at least ' $t$ ', that is, the probability that the random variable $T$ exceeds $t$. The distribution of $\mathrm{T}$ is characterized differently in the Hazard function, which is sometimes called the instantaneous occurrences of the event. The Hazard function is (Dadi et al., 2004):

$h t=\lim _{\Delta t \rightarrow \infty}\left(\frac{\operatorname{pr}\left(t<T<t+\Delta t t_{-} \geq t\right.}{\Delta t}\right)$

The numerator of (2) gives the conditional probability that a crossbred will be adopted in the interval, $(\mathrm{t}, \mathrm{t}+\mathrm{dt})$ given that $\mathrm{a}$ crossbred has not been adopted before. The denominator is the size of this interval. When the width of this interval approaches zero it is the instantaneous rate of occurrence (=adoption), stated as:

$=\lim _{\Delta t \rightarrow 0} \frac{F(t+\Delta)-F(t))}{\Delta S(t)}=\frac{F(t)}{S(t)}$

where, $\mathrm{S}(\mathrm{t})$ is the survival function and $\mathrm{F}(\mathrm{t})$ is the continuous probability density function.

\section{Parametric Model}

The most commonly used parametric model in duration analysis is the Proportional Hazard model and it takes the following form:

$h(t, X, \theta, \beta)=h_{0}(t, \theta) g(X, \beta)$

where, $h_{0}(t, \theta)$ is the baseline hazard, $g(X \beta)$ is the scaling factor, and $\theta, \beta$ are parameters to be estimated (An and Butler, 2012). There are three types of proportional hazard models in literature: the, Exponential, Weibull and Gompertz models. The exponential model is characterized by a constant hazard function, $h(t)=\lambda$ where, the parameter $\lambda$ is more than zero, implying that the time does not influence the hazard rate. The Weibull model is defined by the hazard function $\mathrm{h}(\mathrm{t})=\lambda$ pt $\mathrm{p}-1$ with $\lambda>0$ and $\mathrm{P}>0$. If $\mathrm{P}>1$, then risk increases over time. If $\mathrm{P}<1$, risk declines over time. If $\mathrm{P}=1$, this model collapses to an exponential model where, risk is constant over time (Alcon et al., 2011). In the Gompertz model the hazard function is defined as $\mathrm{h}(\mathrm{t})=\lambda \exp (\gamma \mathrm{t})$. When $\gamma$ becomes positive, the hazard function tends to increase with time. However, when it is negative, the hazard function decreases with time. The hazard function is equal to $\lambda$ for all $\mathrm{t}$ when $\gamma=0$ and therefore, the model reduces to exponential. In addition to time, evaluating the explanatory variables that influence the distribution of durations is of interest. Thus, the hazard function can be made to condition on a vector of explanatory variables in matrix, $x$. The estimated $\beta$ in (4) indicates the direction and proportional effects of unit changes in the relevant explanatory variables on the conditional probability of adoption at time $t$ (Dadi et al., 2004). In this research, four (Cox, Exponential Gompertz and Weibull) models were estimated.

\section{Sample Collection and Data Analysis}

Two hundred and one samples were collected from the three agro-ecological zones (Table 2). Data collection was done using a structured questionnaire. We pretested the questionnaire with 20 farmers prior to the formal survey. The formal survey was conducted from January to April in 2009. Three trained enumerators conducted face-to-face interviews with farmers. Each interview lasted about 20 minutes. 
Table 2: Allocation of the sample to the study areas

\begin{tabular}{lcr}
\hline $\begin{array}{l}\text { Agro-ecological } \\
\text { zone }\end{array}$ & $\begin{array}{c}\text { Number of } \\
\text { households }\end{array}$ & Percentage \\
\hline Dry Zone & 71 & 35.32 \\
Intermediate zone & 81 & 40.30 \\
Wet zone & 49 & 24.38 \\
TOTAL & 201 & 100.00 \\
\hline
\end{tabular}

\section{RESULTS AND DISCUSSION}

\section{Sample Features}

Descriptive statistics of the sample of cattle farmers and variables used in the models are given in Table 3.

Table 3: Descriptive statistics of the sample

\begin{tabular}{|c|c|c|c|c|}
\hline Variables & Category & Percent & Mean & $\begin{array}{l}\text { Standard } \\
\text { Deviation }\end{array}$ \\
\hline \multirow{3}{*}{$\begin{array}{l}\text { Agro- } \\
\text { climate }\end{array}$} & Wet zone & 35.32 & - & - \\
\hline & $\begin{array}{l}\text { Intermediat } \\
\mathrm{e}\end{array}$ & 40.30 & - & - \\
\hline & Dry zone & 24.38 & - & - \\
\hline Gender & $\begin{array}{l}\text { Male } \\
\text { Female }\end{array}$ & $\begin{array}{l}20.90 \\
79.10\end{array}$ & - & - \\
\hline Age & - & - & 47.20 & 11.69 \\
\hline Education & - & - & 7.23 & 3.13 \\
\hline \multicolumn{2}{|c|}{$\begin{array}{l}\text { Cooperative Yes } \\
\text { membershipNo }\end{array}$} & $\begin{array}{l}67.66 \\
32.34\end{array}$ & - & - \\
\hline $\begin{array}{l}\text { Extension } \\
\text { visits }\end{array}$ & - & - & 2.70 & 4.91 \\
\hline Managemen & Intensive & 8 & & \\
\hline \multirow[t]{2}{*}{ t system } & semi intens & sive 45 & & \\
\hline & Extensive & 47 & & \\
\hline $\begin{array}{l}\text { Extension } \\
\text { Visits }\end{array}$ & & & 2.7 & \\
\hline crossbreeds & Yes & 76 & & \\
\hline & No & 24 & & \\
\hline
\end{tabular}

The majority of respondents are male (79\%) with an average age of 47 years. Considerable amount of respondents have a formal schooling up to secondary school (Figure 1).

This is in line with the high literacy levels seen in Sri Lanka. More than 80 percent of farmers were engaged in dairy farming as a fulltime occupation while around 18 percent of the farmers were in dairy farming as a part time operation, while being employed elsewhere.

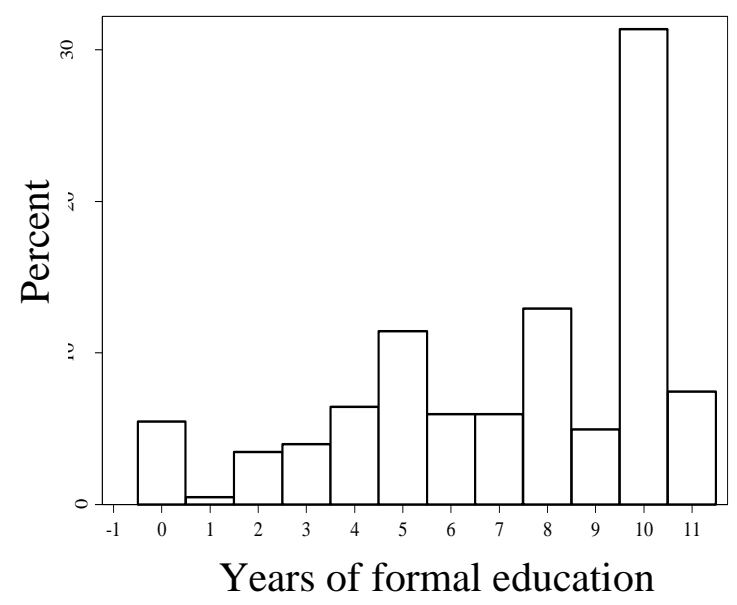

Figure 1: Years of formal schooling by farmers in the sample

Majority of farmers carried out a semi intensive (45\%) or extensive systems (47\%) in cattle rearing with an average herd size of eight. The majority of farmers has a membership with a milk cooperation (68\%) which is an institutional innovation that reduces transaction costs of farmers considerably (Holloway et al., 2000). An extension agent visits a farmer 2.7 time per year on average. At the time of the survey, about 76 percent of the farmers had adopted the crossbred cow technology. The key variable in this research was the adoption duration. We measured the duration by the time from starting dairy farming to the date where a farmer has first bought a crossbred cow. The earliest year of adoption in the sample was 1965 and the maximum duration of adoption was 45 years. The average duration was seven years. The Kaplan-Meier estimate of the step survivor function is in Figure 2, a non-parametric approach without any assumptions on the distribution of the survival times (Burton et al., 2003). 
The horizontal axis represents 44 years between the first adoption year, 1965, and the year of survey, 2009, is scaled in artificial enter into the function as all are treated as non-adopters where the value of the function is 1 time, from 0 to 50 .

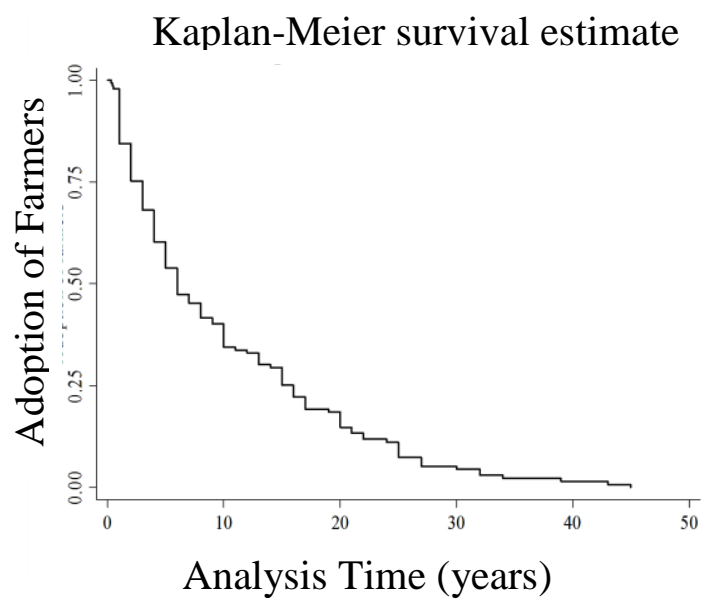

Figure 2. Kaplan-Meier survival estimates

At the point $t=0$, all cases It falls sharply in the first year to $50 \%$ where half of the sample has adopted in the first year of operation. Then the value decreases gradually. There were adopters in each consecutive 10 years giving an evenly spaced step, after which there were long periods with no adoptions and accordingly the Kaplan-Meier survivor function did not change. The last change in the value of the function occurred when the last of the adoptions occurred, at $\mathrm{t}=43$.

\section{Outcomes of the Parametric Estimation of the Duration Model}

Table 4 reports results of all four models estimated: Cox, Exponential Gompertz and Weibull. The Cox model is a semiparametric model while the Exponential, Gompertz and Weibull models are parametric. The Cox model avoids imposing parametric form on the baseline hazard while the other three does. That is, in
Cox model, the distribution of the survival time is not known while in the parametric models, this distribution is assumed to be either exponential (exponential model), Gompertz (Gompertz model) or Weibull (Weibull model).

Table 4: Results of duration analysis

\begin{tabular}{|c|c|c|c|c|}
\hline & Cox & $\begin{array}{l}\text { Exponenti } \\
\text { al }\end{array}$ & Gompertz & Weibull \\
\hline $\begin{array}{l}\text { Intermediate } \\
\text { zone }\end{array}$ & 0.92 & .96 & 0.95 & 0.96 \\
\hline Wet zone & 1.16 & 1.16 & 1.18 & 1.18 \\
\hline Gender & 0.79 & .81 & 0.77 & 0.78 \\
\hline Age & $\begin{array}{l}0.97 * * \\
*\end{array}$ & $.97 * * *$ & $0.97 * * *$ & $0.97 * * *$ \\
\hline Education & $1.08 * *$ & $1.07 * *$ & $1.08 * *$ & $1.08 * *$ \\
\hline $\begin{array}{l}\text { Cooperative } \\
\text { membership }\end{array}$ & $1.43^{* *}$ & $1.39 * *$ & $1.46^{* *}$ & $1.45 * *$ \\
\hline $\begin{array}{l}\text { Extension } \\
\text { visits }\end{array}$ & 1.00 & 1.00 & 1.00 & 1.00 \\
\hline Gamma & - & - & $0.03^{* * *}$ & - \\
\hline $\ln \mathrm{p}$ & - & - & - & $0.15^{* * *}$ \\
\hline$P$ & - & - & - & 1.16 \\
\hline $1 / \mathrm{p}$ & - & - & - & 0.86 \\
\hline
\end{tabular}

Note: Numbers reported are Hazard ratios, $* * *$ and ** shows significance at $p<0.01$ and $p<0.05$ respectively

In reading Table 4, it should be noted that a hazard ratio greater than one denote that the variable has a positive impact on the likelihood of non-adoption spell ending (or the likelihood of adoption) and vice versa. We found that the significance of variables was similar in all models. We made a model comparison by calculating the log-likelihood Akaike Information Criterion (AIC) and Bayesian Information Criterion (BIC) (Table 5).

For the better model, log-likelihood should be higher but AIC and BIC should be smaller. We noted that all three measures of model comparison yielded more or less the same result: the Gompertz model fitted with our data better. In the Gompertz model, we found that gamma was positive 
indicating that the adoption increased exponentially over time (Figure 3).

Table 5: Results of model comparison tests

\begin{tabular}{llll}
\hline Model & $\begin{array}{l}\text { Log } \\
\text { likelih } \\
\text { ood }\end{array}$ & AIC & BIC \\
\hline Cox Proportional & - & 1105.23 & 112 \\
Hazard & 545.62 & & 5.92 \\
Exponential & - & 422.62 & 446. \\
& 203.31 & & 27 \\
Gompertz & - & 417.81 & 444. \\
& 199.91 & & 41 \\
Weibul & - & 420.18 & 446. \\
& 201.09 & & 78 \\
\hline
\end{tabular}

$\overline{A I C}=$ Akaike Information Criterion, BIC $=$ Bayesian Information Criterion

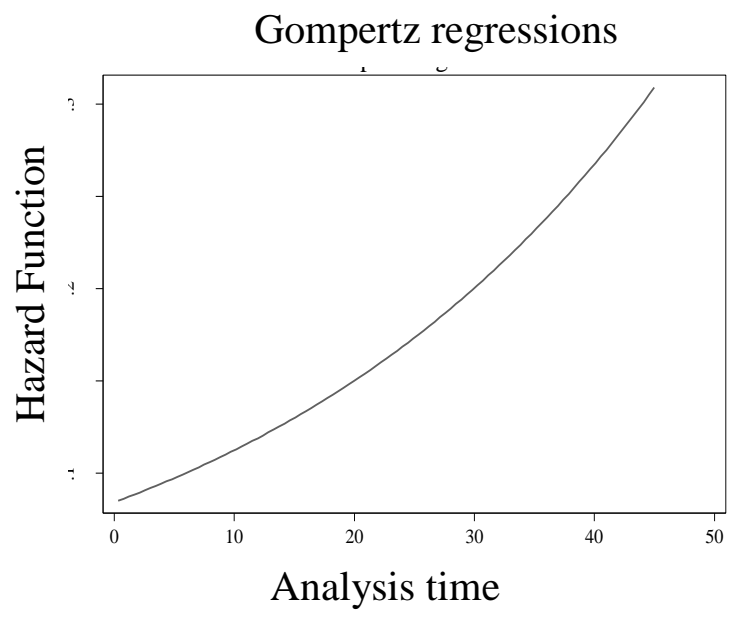

Figure 3: Hazard function from the Gompertz model with all covariates at their mean level

The significance of coefficients were consistent across all models estimated. The overarching finding is that human capital (education) and social capital (cooperative membership) are important covariates that shorten the time taken to adoption. Educated farmers are able to comprehend the benefits of different technologies and therefore make more efficient adoption decisions strengthening the human capital theory (Abdulai and Huffman, 2005). The positive impact of education is evident in most of the previous studies on adoption of technology. Abdulai and Huffman (2005) found that the farmers' years of schooling reduces time to adoption of crossbred cows in Tanzania. Foltz and Chang (2002) found that the increase in education has a positive effect on recombinant Bovine Somatotropin (rbST) usage intensity in Connecticut dairy farms. The membership of milk cooperatives reports the highest hazard ratio irrespective of the model used. Farmer groups are important institutional innovations especially in smallholder context where bargaining power of small farmers is not strong. Cooperatives benefit farmers in many ways. It reduces transaction costs in selling by bulking the produce of small farmers, assured supply of right inputs at the right time, assured market for output etc. (Holloway et al., 2000). Cooperatives are places where farmers meet, exchange knowledge and experiences and therefore, may reduce the time to adoption. It is also noteworthy that the significant coefficient on age which is less than unity, implying that older farmers tend to adopt late. In other words, younger farmers adopt sooner than older. This may have to do with the risk taking behavior of farmers. Younger are more risk preferred than the older. According to the information collected, extension service fail to show significance, although, in many other studies (Sunding and Zilberman, 2001; Kaliba et al., 2000; Abdulai and Huffman, 2005), it has shown significance. One reason may be that there is no proper extension service with respect to animal production although availability of welldeveloped extension service in crop cultivation. Farmers get extension input mainly from buyers who provide some sort of extension services to their clients. We also failed to show significant impact of the agro-climatic zone on the duration of adoption. 


\section{CONCLUSION}

We attempted to study the basic question of how to make the diffusion of crossbred cow technology faster amongst smallholder dairy farmers. In doing so, we estimated one semi-parametric and three parametric hazard functions to assess the robustness of significant variables across such commonly used models in duration analysis. We found that all four models performed similarly, especially with relation to variable significance. However, model comparison statistics showed that Gompertz model fitted with the present data set better than the other three competing models. Our results showed that having human capital increasing variables such as more formal schooling, and social capital increasing variables such as being a member of a milk cooperative significantly reduce the time to adoption while age of the farmer tends to increase the time to adoption. Therefore, it is important to strengthen the institutional innovations such as dairy cooperatives in the country. Also due to the importance of human capital in diffusion of technology it is prudent to develop human capital in the sector for faster diffusion of this important technology amongst the small farmers.

\section{REFERENCES}

Abdulai, A. and Huffman, W.E. (2005). The diffusion of new agricultural technologies: the case of crossbredcow technology in Tanzania, American Journal of Agricultural Economics, 87(3): 645-659.

Alcon, F., Miguel, M. D. \& Burton, M. (2011). Duration analysis of adoption of drip irrigation technology in southeastern Spain. Technological Forecasting and Social Change Technol Forecast Soc Change. 78.
991-1001.

10.1016/j.techfore.2011.02.001

An, H., and Butler, L.J. (2012), A discrete time duration analysis of technology dis-adoption: The case of rbST in California, Canadian Journal of Agricultural Economics, 60: 495-515.

Bandara, B.H.W.M.U.S (2001). The current status of smallholder dairy systems in Sri Lanka. Proceedings of a SouthSouth workshop held at National Dairy Development Board (NDDB), Anand, India, 22-32

Burton, M., Rigby D. and Young, T. (2003) Modeling the adoption of organic horticultural technology in the UK using duration analysis, Australian Journal of Agricultural and Resource Economics, 47(1): 29-54.

Dadi, L., Burton, M. and Ozanne, A. (2004) Duration analysis of technological adoption in Ethiopian agriculture, Journal of Agricultural Economics, 55 (3): 613-631.

Department of Census and Statistics (2002). Census of Agriculture 2002: smallholding sector. Retrieved September 07, 2009, from http://www.statistics.gov.lk/agricultu re/AGC2002/AGC2002.htm

Foltz, J. D. and Chang, H. (2002), The adoption and profitability of rbST on Connecticut Dairy Farms, American Journal of Agricultural Economics, 84(4): 1021-1032.

Holloway, G., Nicholson, C., Delgado, C., Staal, S. and Ehui, S. (2000), Agro industrialization through institutional innovation transaction costs, cooperatives and milk-market development in the east-African highlands, Agricultural Economics, 23(3): 279-288.

Kaliba, A. R. M., Verkuijl, H. and Mwangi, W. (2000), Factors affecting adoption of improved maize seeds and use of 
inorganic fertilizer for maize production in the intermediate and lowland zones of Tanzania, Journal of Agricultural and Applied Economics, 32: 35-48.

Karshena, M. and Stoneman, P. (1995). Technological Diffusion, Handbook of Economic of Innovation and technological change, Blackwell Handbook of Economics, Oxford.

The Ministry of Livestock Development. (2007). The livestock sector in Sri Lanka. Available at ttp://www.livestock.gov.lk/, accessed September, 2009

Mtumwa, A. and Mwasha, P. S. (1995). The strategy for dairy development in Tanzania. $22^{\text {nd }}$ Scientific conference of the tanzanian society of animal production, Dar es Salaam

Sunding, D. and Zilberman, D. (2001). The agricultural innovation process: research and technology adoption in a changing agricultural sector, Handbooks In Economics. 18, 207262. 